\title{
Use of Low Temperature SEM to Study Difficult Organisms
}

\author{
Gary R. Bauchan*, Ron Ochoa ${ }^{* *}$, Jenny Beard $^{* * *}$, Eric Erbe* and Christopher Pooley*
}

* USDA- ARS, Electron \& Confocal Microscopy Unit, Building 465, BARC-East, Beltsville, MD 20705 gary.bauchan@ars.usda.gov

** USDA-ARS, Systematic Entomology Laboratory, Building 005, BARC-West, Beltsville, MD 20705

*** University of Maryland, Entomology Dept., College Park, MD 20740

Resolving the true fine structure and behavior of soft bodied organisms such as insect larvae, mites, nematodes, parasites, bacteria and fungi by scanning electron microscopy has been difficult. Classical preparation techniques, involving immersion fixation, dehydration and critical point drying cause significant deleterious changes in specimen structure due to effects of surface tension, osmotic stress and mechanical damage. The intact exoskeleton, cuticle or other bounding membranes of these organisms, creates a formidable obstacle to the penetration of fixatives and solvents, which are only effective after long periods of time (hours). During this period, behavioral and much of the true structural integrity are compromised and most organisms detach from their hosts.

Our research has utilized methods in low temperature freeze stabilization, to preserve and observe the undisturbed fine structure of biological samples. Plunge freezing into liquid nitrogen, although more rapid, results in many parasitic organisms dislodging from hosts and being lost. Alternatively, freezing by contact with a pre-cooled $\left(-196^{\circ} \mathrm{C}\right)$ brass tube, captures organisms in their natural state as well as their behaviors. Although slow freezing rates can produce large ice crystals internally, exterior surface manifestations are few, organism dislodgement is minimal and structure is remarkably preserved.

Our studies using this methodology along with the use of a cryo-transfer system by Quorum Technologies Ltd., allows us to transfer ultra frozen samples into a Hitachi FE 4700 SEM. Observations of the benefits of contact freeze-stabilization for visualizing delicate, fast moving, soft bodied organisms while maintaining their true three-dimensional gross and fine structure as well as behavioral positions on their hosts will be presented. Numerous soft bodied organisms including mites [1], nematodes [2], parasites [3] and fungi [4] have been used to illustrate the efficacy of this technique. Collapse and destruction of delicate features and gross structure is prevented and host/parasite associations are maintained and we have shown that DNA can be extracted and analyzed from these specimens [5]. A frozen frame of life is preserved for study. Utilization of low temperature SEM is far superior to standard light microscopic studies of these difficult organisms Figure 1.

[1] E.Gamliel-Atinsky, et al., Exp. Appl. Ararol. 51 (2010) 191-204.

[2] L.K. Carta, et al., J. Nematology 42 (2010) 191-209.

[3] Macarisin, et al. J. Food Protection. 73 (2010) 1824-1829.

[4] Wen, Y, et al. J. Exp. Bot. (2010) doi: 10.1093/jxb/erq406.

[5] Dowling, A. .P.G. Acrologia. 50 (2010) 479-485. 


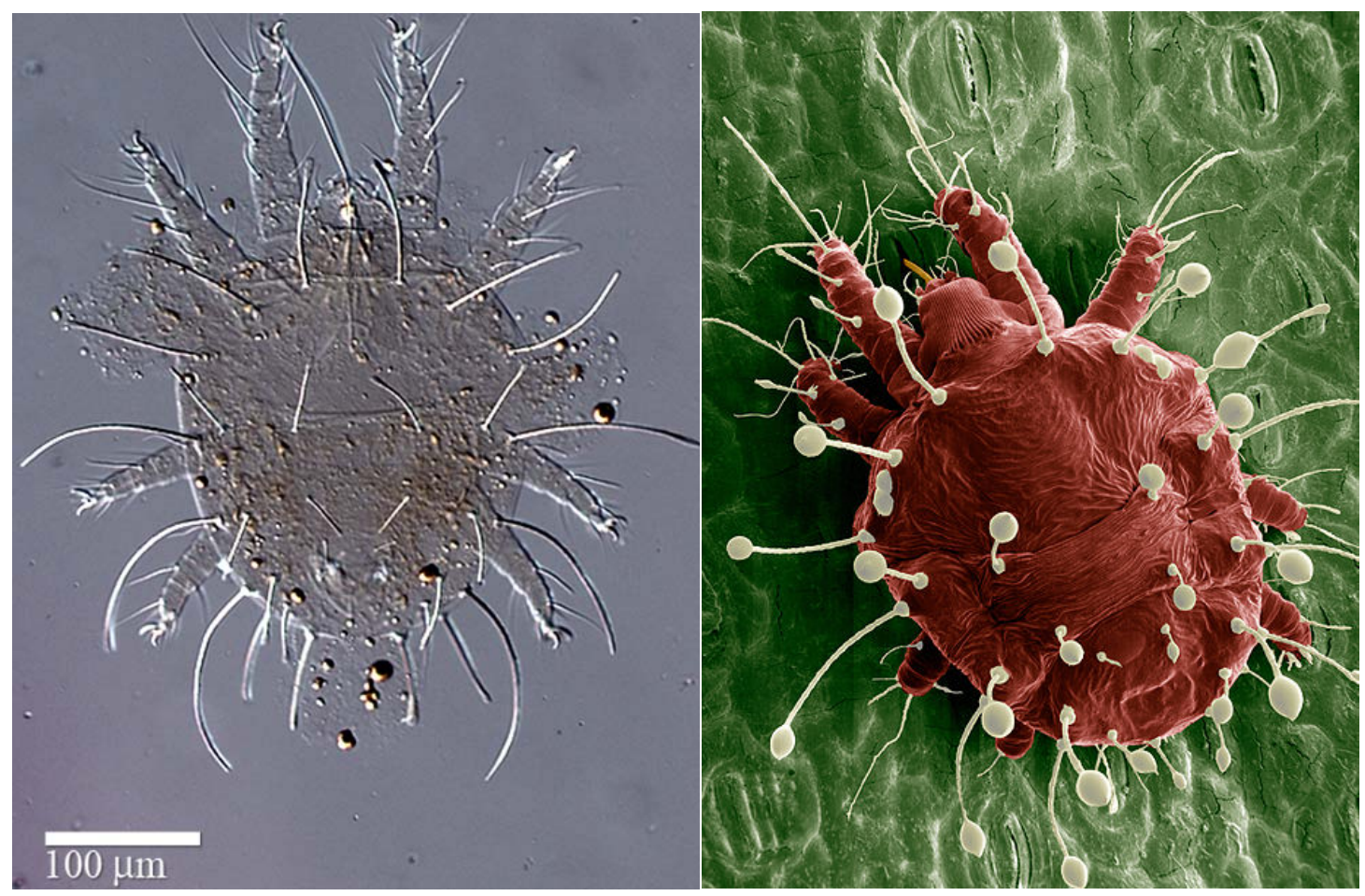

Figure 1, Light Microscope image of mite Raoiella indica on left low temperature SEM on right. 